\title{
Life cycle assessment of refurbishment scenarios to confined tank structures at a waste water treatment plant
}

\author{
Michel Donadio ${ }^{1}$, Catrina Heider $^{2}$, Zeno Dan $^{3}$ \\ ${ }^{1}$ Sika Services AG, Switzerland \\ ${ }^{2}$ Sika Technology AG, Switzerland \\ ${ }^{3}$ Sika Europe Management AG, Switzerland
}

\begin{abstract}
The paper will show a Life Cycle Assessment (LCA) of three different refurbishment scenarios for confined tank structures at a waste water treatment plant. - One using a traditional Portland cement based repair mortar, one combining this cement repair mortar with a reactive protective coating, and one using $100 \%$ calcium aluminate based repair mortar technology. In order to evaluate the sustainability and potential environmental impact of each of the three scenarios, the Life Cycle Assessments (LCA) were performed, which included Cumulative Energy Demand (CED), Global Warning Potential (GWP) and Photochemical Ozone Creation Potential (POCP). The results are compared and analyzed in this paper, particularly in relation to extending the structural service life, which shows how innovative systems can give advantages to designers and contractors, which in turn are also of benefit to their customers.
\end{abstract}

\section{Introduction}

Sewers and confined tanks in waste water treatment plants often suffer from biogenic corrosion in their areal zones. This biogenic corrosion [1] occurs because of the transformation of the sulfates present in domestic waste water into hydrogen sulphide gas and then subsequently into sulphuric acid by different strains of bacteria.

The sulphuric acid attacks all types of mineral substrates severely. Traditionally, concrete repair systems with reactive resins are used, but these require defect-free conditions and application, which are often impossible to achieve in such difficult environments.

In the last 20 years, $100 \%$ calcium aluminate based mortars (cement \& aggregates) have been used to successfully renovate these structures. One of the main features of this technology is its ability to block the transformation of hydrogen sulphide into sulphuric acid, due to the bacterio-static effect of calcium aluminate mortar. This has already been explored in various published papers [1], [2], [3].

Therefore, choosing the right repair strategy and product quality not only significantly reduces the frequency of refurbishment cycles, but will also have a positive impact on the structure's longevity, and on the overall economic performance of the structure.

The main sustainability aspects for refurbishment are thus related to the normal three pillars of sustainability (social, economic and environmental), through the main drivers:

Materials input, time efficiency, economic costs and environmental impacts.
To examine these, three different refurbishment scenarios for the refurbishment of a confined tank structure $\left(1,000 \mathrm{~m}^{2}\right)$, are compared in this paper for their environmental impact, durability and cost effectiveness.

\section{Method}

Life Cycle Assessment (LCA) [4] provides a method to quantify and evaluate potential environmental impacts throughout a product's life cycle. It starts with the raw materials, through the production phase, on to the site; then through the products' use, service life and end of life treatment, either to waste incineration, or its recycling can be included. This is commonly referred to as cradle to grave in the standard ISO 14044 (ISO 2006). In this study, the production module (cradle to gate) and the surface pre-treatment were considered in the assessment.

An LCA for a construction material manufacturer can produce a quantitative environmental profile within a defined framework, which can help to improve or differentiate between products and solutions in terms of their potential environmental benefits. This LCA of alternative refurbishment systems and products was performed by the Sika Global Product Sustainability Department according to ISO 14044 (ISO 2006) and EN 15804 (CEN/TC 350 2012). 


\section{Scope of the analysis}

The functional unit taken for the LCA is the refurbishment of an arbitrary confined reinforced concrete tank in a waste water treatment with a surface area of $1,000 \mathrm{~m}^{2}$ over a 50 year life span.

It is assumed that this internal tank surface is subjected to biogenic corrosion on the areal part of the structure. To perform the LCA, an inventory analysis was necessary, i.e., data collection and calculation procedures to quantify all of the relevant inputs and outputs of the procedures and products in each system.

The product data collection was carried out by the respective manufacturer and corresponds to the measured or qualified data, including the product formulations, transportation, packaging and production. The systems were then modelled in the LCA software $\mathrm{GaBi}$ 8.7.0 [5], based on this data and datasets from commercial databases such as ELCD (European Reference Life Cycle Database), Thinkstep and Ecoinvent. The materials' transport to the site, their installation (excepting the surface pre-treatment) and their end of life treatment were excluded from this LCA.

The impact assessment phase associates inventory data with environmental impact categories (calculated with the CML 2001 method). Three impact categories are considered to be the most relevant for this example, as these three depict the sustainability drivers in refurbishment: the carbon footprint, resource (and energy) efficiency, and pollutant emissions (also related to health and safety of the workers).

\subsection{Cumulative energy demand}

Cumulative Energy Demand (CED) reflects the total input of primary energy from renewable and nonrenewable resources. It is measured in MJ.

\subsection{Global warming potential}

The global warming potential (GWP) is the potential contribution to climate change due to greenhouse gases emissions. It is measured in $\mathrm{kg}$ (or tons) of carbon dioxide $\left(\mathrm{CO}_{2}\right)$ equivalent for a 100 -year time horizon.

\subsection{Photochemical ozone creation potential}

Photochemical ozone creation (POCP) is the potential contribution to summer smog, related to ozone induced by sunlight on volatile organic compounds (VOC) and nitrous oxides (NOx). It is measured in $\mathrm{kg}$ of ethene equivalents (also known as ethylene).

\section{Retrofitting scenarios analysed}

The different systems are calculated over a 50 year period based on an arbitrary surface area of 1,000 $\mathrm{m}^{2}$. The scenarios and products are described below.

\subsection{Description of the scenarios}

There were three different scenarios selected for comparison. The first scenario assumes the refurbishment is carried out with a CEM III based concrete repair mortar complying with EN 1504-3 and achieving the highest performance classification of R4 (Cement used being sulfate resistant). Based on site returns and lab assessment, it is assumed that the full cover of $50 \mathrm{~mm}$ would need to be replaced every 7 years to provide corrosion protection to the reinforcing bars.

The second scenario uses the a polymer modified R4 class CEM III mortar complying to EN 1504-3 followed by an epoxy cement combination coating that provides a temporary moisture barrier and a smooth surface suitable for the use of a $100 \%$ solid epoxy top coating. Based on site returns, we have assumed this would need to be replaced every 10 years.

The third scenario uses a repair mortar based on calcium aluminate technology (both the cement matrix and aggregates being calcium aluminate based). As the aluminate matrix inhibits the transformation of the $\mathrm{H}_{2} \mathrm{~S}$ into sulphuric acid [1], longer term durability [6] can be achieved, so for this LCA, we assumed this would need to be replaced only once over the 50 year design period.

\subsection{Detailed application information}

\subsubsection{Scenario 1}

Retrofitting every $\mathbf{7}$ years with repair mortar; no protective coating after the mortar application:

- Surface Preparation by high pressure water

- Reprofiling with concrete repair mortar over 50 $\mathrm{mm}$ with wet spray application (100 tonnes per retrofitting).

\subsubsection{Scenario 2}

Retrofitting every 10 years with repair mortar; epoxy protective coating after the mortar application:

- Surface Preparation by high pressure water

- Reprofiling with concrete repair mortar over 25 $\mathrm{mm}$ by wet spray application (50 tonnes per retrofitting)

- $\quad$ Resurfacing and temporary moisture barrier over 3 mm thick by wet spray application $(1030 \mathrm{~kg}$ per retrofitting)

- $\quad$ Concrete protection with 2 coats of epoxy coating $@ 500 \mathrm{~g} / \mathrm{m}^{2}$ per coat, by airless application (16 tonnes per retrofitting)

\subsubsection{Scenario 3}

Retrofitting once over the designed period:

- Surface Preparation by high pressure water

- Reprofiling with Calcium Aluminate concrete repair mortar over $25 \mathrm{~mm}$ by wet spray application (60 tonnes) 


\subsection{Product description}

Table 1: The refurbishment materials

\begin{tabular}{|c|c|}
\hline $\begin{array}{l}\text { Product } \\
\text { Type }\end{array}$ & Description \\
\hline \multicolumn{2}{|l|}{ Scenario 1} \\
\hline Repair mortar & $\begin{array}{l}\text { 1-component, non-polymer modified (CC), } \\
\text { R4 repair mortar complying with EN 1504-3 }\end{array}$ \\
\hline \multicolumn{2}{|l|}{ Scenario 2} \\
\hline Repair mortar & $\begin{array}{l}\text { 1-component, polymer modified (PCC), R4 } \\
\text { repair mortar complying with EN } 1504-3\end{array}$ \\
\hline $\begin{array}{l}\text { Resurfacing } \\
\text { mortar }\end{array}$ & $\begin{array}{l}\text { 3-component resurfacing mortar complying } \\
\text { with EN } 1504-3 \text { and }-2 \text {, not requiring any } \\
\text { curing and allowing fast over-coating with an } \\
\text { epoxy resin }\end{array}$ \\
\hline $\begin{array}{l}\text { Epoxy } \\
\text { coating }\end{array}$ & $\begin{array}{l}\text { Protective coating complying with EN } 1504-2 \\
-100 \% \text { solids content }\end{array}$ \\
\hline \multicolumn{2}{|l|}{ Scenario 3} \\
\hline Repair mortar & $\begin{array}{l}\text { 1-component, } 100 \% \text { Calcium Aluminate } \\
\text { mortar, R4 repair mortar complying with EN } \\
1504-3\end{array}$ \\
\hline
\end{tabular}

\section{LCA Results}

The actual LCA analysis is a complex analysis. For simplicity the illustrated graphs below present a summary from the study, showing the overall impact on the three categories (refer to Fig. 1, 2, 3, 4 \& 5).

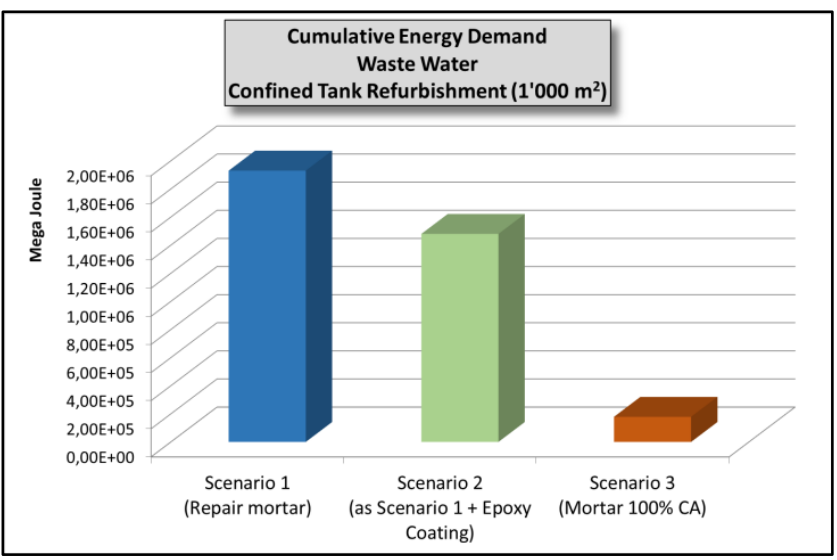

Fig. 1: Cumulative Energy Demand for a lifespan of 50 years.

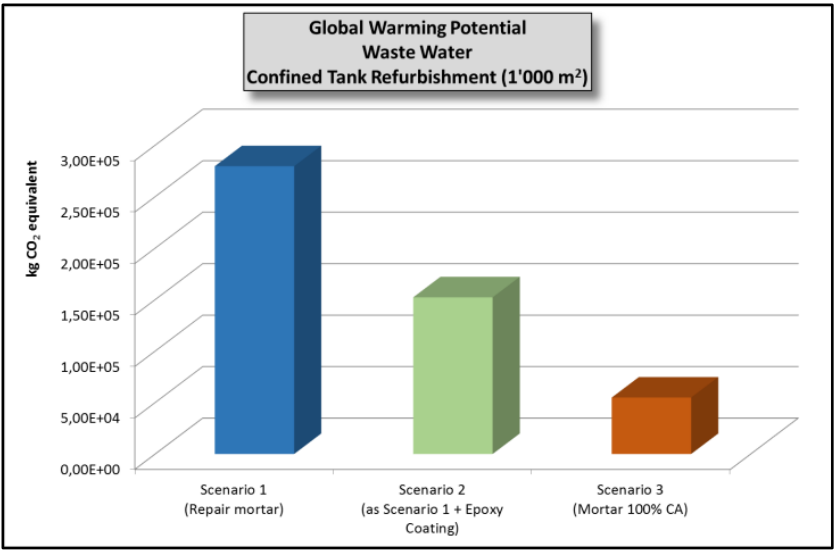

Fig. 2: Global Warming Potential, for a lifespan of 50 years.

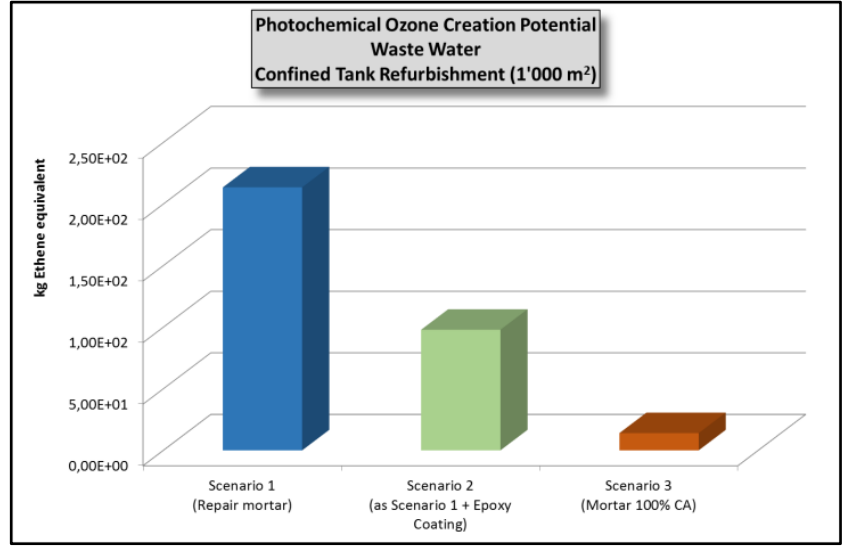

Fig. 3: Photochemical Ozone Creation Potential for a lifespan of 50 years.

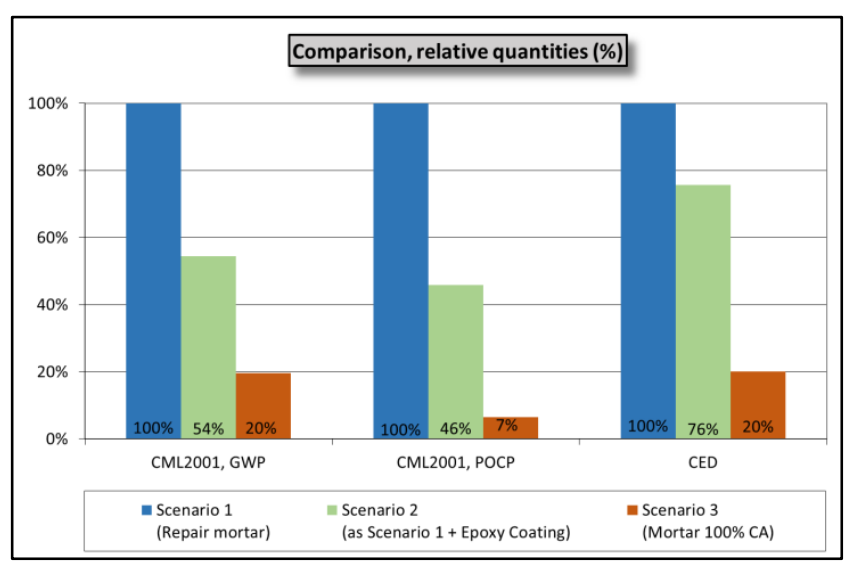

Fig. 4: Comparison of the three categories - Scenario 1 being used as reference.

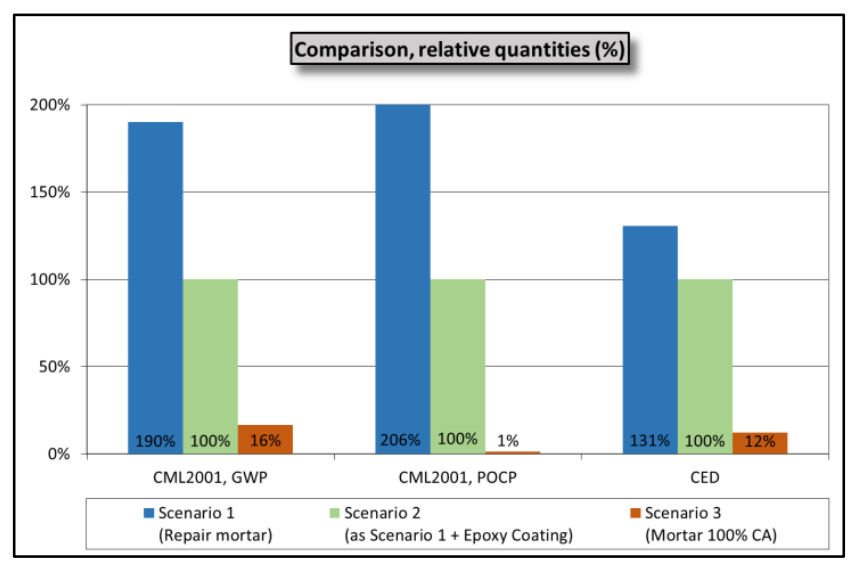

Fig. 5: Comparison of the three categories - Scenario 2 being used as reference.

\section{Discussion}

\subsection{Scenario-1}

Scenario-1 entails higher environmental impact in the three categories compared to the others. This is due to the necessary repetition of the retrofitting, as all types of Ordinary Portland Cement based system are very sensitive to acid attack generated by biogenic activities. 

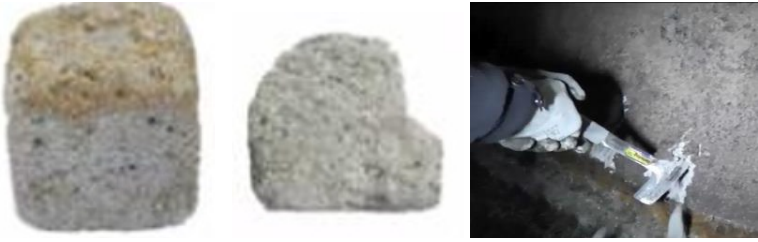

Fig. 6 \& 7: OPC mortar containing fly ash, silica fume and silica sand after 1 year in an incubation chamber simulating the biogenic corrosion - the picture on the left being the cube at the start of the test and the one in the middle at 1 year later (3).

Fig. 8: The picture on the right is in a large waste collector near Paris, where a repair mortar is being scratched off easily, due to its deterioration by biogenic corrosion, just a few years after the installation.

\subsection{Scenario-2}

Scenario-2 also has significant impact in each of the three categories; though lower than Scenario-1.

This is because the system comprises epoxy resin based materials that have some environmental impact.

Additionally, the relatively frequent repetition of the retrofitting being required, also increases this impact.

\subsection{Scenario-3}

Scenario-3 has the lowest environmental impact in all of the three categories.

This is due to the long service life and durability of the calcium aluminate based repair mortar in this type of environment. Investigations in incubation chambers [6] and in real-life similar environments have shown that these mortars have a very low degradation rate.

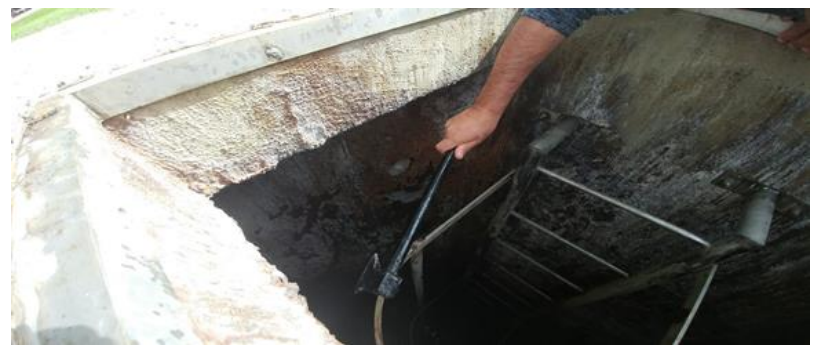

Fig. 9: Picture taken in Israel where a system similar to Scenario-2 has shown premature failure after just 5 years in service.

\subsection{Cumulative energy demand}

Scenario-3 has the lowest impact to primary energy from renewable and non-renewable resources.

When compared to the Scenario-1, the energy saving per year using the $100 \%$ calcium aluminate mortar is equivalent to the energy required to produce $\sim 40$ tons of oil (and to $\sim 28$ tons of oil when compared to the system used in Scenario-2).

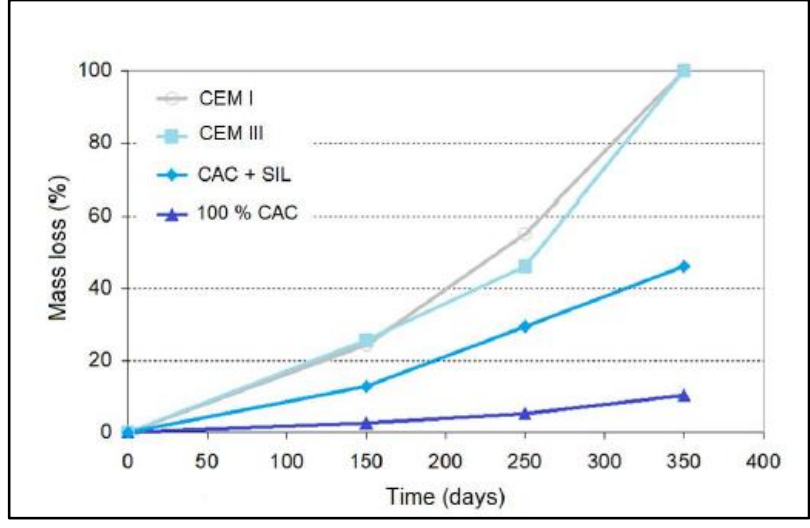

Fig. 10: Weight loss over time from four cementitious materials exposed in the Hamburg Simulation Chamber [6] for one year.
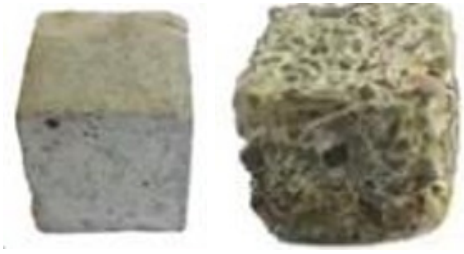

Fig. 11: Cube of 100\% CAC mortar exposed in the Hamburg Simulation [6] for 1 year. Left-hand picture was taken at the start of the test, with the right-hand picture taken 1 year later.

\subsection{Global warming potential}

Using the $100 \%$ Calcium Aluminate technology will minimise the potential contribution to climate change by significantly reducing the emissions of carbon dioxide.

When compared to Scenario-1, the $\mathrm{CO}_{2}$ saving per year using the $100 \%$ calcium aluminate mortar is equivalent to the $\mathrm{CO}_{2}$ issued during the transport of 24.7 Tonnes (typical full truck capacity) of product by truck for over $\sim 150$ '000 km, which is equivalent to more than three times the worlds circumference (the figure is still approx. half this amount for Scenario-2 at $\sim 67^{\prime} 000 \mathrm{~km}$ ).

\subsection{Photochemical ozone creation potential}

Scenario-3 also has the lowest impact in the category of ozone creation potential.

When compared to the Scenario-1, the VOC saving per year using the $100 \%$ calcium aluminate mortar is equivalent to saving $\sim 115$ tons of solvent based coating (the figure is $\sim 49$ tons when compared to Scenario-2).

\section{Conclusions}

Biogenic corrosion is a growing problem in sewers and waste treatment plants due to various different factors (e.g. the reduction of water consumption, and the reduction of odour leading to the enclosing of many open tanks, etc.).

Field returns have shown repeated failures of traditional repair and retrofitting systems such as those 
described in Scenario-1 \& Scenario-2, leading to repeated retrofitting sequences.

Repetition of these retrofitting procedures not only has an economic impact (materials cost, loss of service, temporary by-pass, etc.), but this imposes a significant impact on the environment as well.

When a suitable $100 \%$ calcium aluminate technology is used to retrofit surfaces affected in this way, or to protect new structures, significant savings can be achieved. This is because, once the application is done, the protected concrete surfaces in the areal zone of the structure will not be affected by biogenic corrosion in future as sulfuric acid is not being produced any longer.

In addition to providing substantial cost \& time savings, the use of this type of mortar significantly decreases the impact to the environment (reductions of 90 to $99 \%$ when compared to Scenario-1 - refer to Fig. 4 above; and reductions of 98 to $83 \%$ when compared to Scenario- 2 - refer to Fig. 5 above).

In conclusion, when compared to traditional refurbishment solutions, the achievements of such a durability orientated system for these confined tanks subject to potential biogenic corrosion over a service life of 50 years can be summarised as follows:

- Higher performance $=$ lower refurbishment frequency and intensity $=$ environmental benefits, plus materials, time and cost savings

- Energy savings (equivalent to $\sim 40$ tonnes of oil)

- Carbon savings (equivalent to transporting a full truck $\sim 150 ’ 000 \mathrm{~km}$ )

- VOC emissions savings (equivalent to saving the use of $\sim 115$ tonnes of solvent based paints).

\section{References}

1. J. Herisson, Thesis: Bio-degradation of cement material in sewer refurbishment - comparative study of aluminate cement and Portland cement. (2012)

2. F. Saucier et all; Use of Calcium Aluminate Technology; The Institute of Concrete technology, (Year book 2015-2016)

3. V.A. Geoffroy et all, Calcium Aluminate Cements: Proceeding of the Centenary Conference, Fentiman $\mathrm{CH}$, Mangabhai RJ and Scrivener KL. (Editors), (2008)

4. CEN/TC 350 2012, Sustainability of construction works - Environmental product declarations - core rules for the product category of construction products, EN 15804:2012, (2011).

5. GabBi 8.7.0; Software-System and Database for Life Cycle Engineering. Thinkstep AG (LeinfeldenEchterdingen), (1992-2018)

6. S. Ehrich \& all, Journal of Materials in Civil Engineering, Biogenic and Corrosion Sulfuric Acid Corrosion of Mortars, (1999) 